\title{
Stress Sensitivity and Signs of Anxiety or Depression among First Year Clinical Dental and Medical Students
}

\author{
Rod Moore* (D), Line Vang Madsen, Mathilde Trans \\ Department of Dentistry and Oral Health, Aarhus University, Aarhus, Denmark \\ Email: *rod.moore@dent.au.dk, linevangmadsen@outlook.dk, mathildetrans@hotmail.com
}

How to cite this paper: Moore, R., Madsen, L.V. and Trans, M. (2020) Stress Sensitivity and Signs of Anxiety or Depression among First Year Clinical Dental and Medical Students. Open Journal of Medical Psychology, 9, 7-20.

https://doi.org/10.4236/ojmp.2020.91002

Received: November 30, 2019

Accepted: December 23, 2019

Published: December 26, 2019

Copyright ( 2020 by author(s) and Scientific Research Publishing Inc. This work is licensed under the Creative Commons Attribution International License (CC BY 4.0).

http://creativecommons.org/licenses/by/4.0/

\begin{abstract}
Background: Negative stress symptoms are reported in the literature among clinical dental and medical students and can include signs of anxiety or depression. However, very little has been researched about existing psychological preconditions of these students that could make them more vulnerable to negative stress symptoms. Objective: The aims were to explore first year clinical dental and medical students' experiences of stress intensity, stress sensitivity and signs of anxiety or depression. Gender was also explored as a possible predictor of these psychosocial phenomena. Methods: First year clinical students at Aarhus University dental $(n=49)$ and medical schools ( $n$ = 59) were recruited to fill out a 45-item questionnaire that comprised demographics and three scales: Cohens Perceived Personal Stress (PPS-10), Stress Sensitivity Inventory (SSI) and Depression Anxiety \& Stress Scale (DASS-21). Groups and genders were compared by frequency and using association statistics, bivariate odds ratios, nominal logistic regression and ANOVA. Results: Stress intensity perceptions were moderate to high for many. Dental students scored higher than medical students on all mean test scores. In general, women showed higher levels of stress than men. Dental students scored significantly higher than medical students on Depression, Anxiety and Chronic Stress with ANOVA tests. However, when gender, age and medical or dental student status were added into a logistic regression analysis in which high stress sensitivity was the main dependent variable, only high scores in perceived stress intensity and signs of depression and anxiety showed significant main effects. Conclusion: Present study confirmed the literature that reports high degrees of stress among dental and medical students. But more importantly, Stress Sensitivity Inventory appeared to be a reliable and excellent predictor of high perceived stress and signs of depression and anxiety. It can be useful to detect and prevent student psychosocial dysfunction in clinical
\end{abstract}


learning environments. An important challenge for medical and dental educational institutions is to provide specific student emotional support as early as needed as well as to consider appropriate stress prevention curriculum reforms.

\section{Keywords}

Perceived Stress, Stress Sensitivity, Anxiety, Depression, Dental Students, Medical Students, Clinical Education, Stress Management

\section{Introduction}

Several studies have shown that dental students [1] [2] [3] [4] and medical students [4] [5] [6] often experience negative stress symptoms during their education, especially in the years of transition from preclinical to clinical competencies [4] [7] [8] [9] [10]. Studies also show that stress intensity levels fall the further medical students progress in their education [4], while dental students' stress levels meaningfully increase in their first clinical year, which is usually the third year [4] [8]. Stress levels were determined with the same measures in these studies.

Causes of adverse stress levels have been reported to be different for dental and medical students. One recent study [7] showed that new Danish clinical dental students experienced stress mostly due to excessive demands and expectations of themselves, as well as concerns about how others perceive them, i.e. external demands from patients, faculty and clinical teachers. Another study [4] showed that medical students, in particular, experience uncertainty about their professional role identity as a stress factor, in which the focus is on responsibility as a qualified doctor. Physicians often face life and death situations leading students to have uncertainty about their competencies. The same study showed that academic performance, patient and clinic responsibilities as well as faculty relationships were stress factors for dental students, which was similar to the study cited above. As soon as dental students started their clinical training, they were given patient responsibility. This is not the case for medical students, who only achieve a similar responsibility after completing their educational extension with clinical rotations [4].

According to the theoretical literature, the intensity of perceived stress depends on two things-the frequency and/or intensity of the stress load and the person's assessment of their ability to deal with the stress stimuli in question [11] [12]. There is no doubt that the stress load of dental and medical students is high and the literature has identified these stress sources in detail (so-called stressors) [1] [2] [3] [4] [9]. In contrast, student assessments of coping with stress are covered less in the literature [13] [14]. The Stress Appraisal theories of Lazarus and Folkman [11] [12] deal with the abilities of individuals to process stress rather than the event load itself. People differ in how they interpret (ap- 
praise) what happens to them and their opportunities to deal with it. A study of Danish medical students [5] reported that even though their level of stress was moderate, almost a third had experienced reactive depressive feelings. This illustrated a tendency toward negative stress appraisal. The same study found that women reported higher levels of stress and at the same time felt more depressed compared to men, but not statistically significantly. The study also showed that students with lower stress levels are less likely to have depressive symptoms.

Regarding negative stress appraisal, the concept of stress sensitivity is also mentioned [15]. While the stress response is essential for maintenance of homeostasis and survival, chronic stress and maladaptive responses to stress loads can lead to anxiety, depression or other affective disorders [16] [17] [18]. A key factor in the mediation of stress reactivity is the neuropeptide corticotropin-releasing factor (CRF). Studies in animal models of heightened stress sensitivity have illustrated the involvement of CRF downstream neurotransmitter targets, including serotonin and norepinephrine, in the profound neurocircuitry failure that may underlie maladaptive coping strategies and affective disorder susceptibility [19] [20] [21] [22]. Therefore, it is important to gain insight into whether there are signs of depression, anxiety or negative stress symptoms among dental and medical students. Clarification of especially those most susceptible to higher levels of these psychological states [16] [17] [18] would contribute to who might need support programs or other preventive measures.

The specific aims of the present study were to investigate new clinical students' perceptions of stress intensity, stress sensitivity levels and associations with any signs of mental disorders. Variations in demographics of age and gender were also studied for comparative associations. The main focus was to be able to gain insight into personal stress sensitivity characteristics that are typical of the two programs, and how these characteristics are associated with perceived stress intensity and signs of mental disorders experienced by students. Results could be important in determining needs for any support programs and preventive measures for those who are most susceptible and have higher levels of these psychological states.

Similar to the literature, we expected to find elevated levels of stress intensity for both academic groups, but we also expected to find that dental students reported higher levels of stress than medical students, given the differences in patient responsibility in the first year. We also expected to find significant differences in stress sensitivity level between men and women, but not necessarily on stress intensity level, regardless of academic group. Furthermore, we expected no significant difference in the amount of pathology (depression, anxiety chronic stress) between dental students and medical students. Finally, we expected significant correlations between stress sensitivity, perceived stress intensity, and signs of mental disorders among these clinical students.

\section{Material and Methods}

Study subjects (Ss) were the entire class of 5th semester dental students in 2018 
$(\mathrm{n}=49)$ and a similar sized convenience sample $(\mathrm{n}=59)$ of 7 th semester medical students at Aarhus University. Subjects were all recruited in classroom settings. While dental students were in compulsory teaching settings, medical students were recruited from noncompulsory teaching but in high rate attendance classes. Both groups had had patient exposure in the first months of their clinical education.

\subsection{Questionnaires}

The subjects were initially asked to sign a participant consent form stating the project's purpose and expectations for participation. They were then asked to complete three paper and pencil questionnaires consisting of 45 items. The subjects were identified only by gender and age, which they noted on the cover of the first page. Signed consent and questionnaires were kept separately, so that participants remained completely anonymous. The 43 questions covered the topics: 1) stress intensity perception, 2) stress sensitivity, and 3) evidence of the signs of mental disorders.

\section{Stress intensity perceptions}

Perceived stress intensity level was measured using Cohens Perceived Personal Stress (PPS-10) [23]. PPS-10 is a validated test of 10 questions about people's global stress level with items answered in ordinal scaling: $0=$ never; $1=$ almost never; 2 = occasionally; 3 = quite often; $4=$ very often. Items reflected a person's reactions during the past month like: 1) being upset over something that happened unexpectedly, 2) feeling like you couldn't control the important things in your life, 3) feeling nervous or stressed, 4) feeling confident in your ability to cope with your personal problems, 5) feeling that things were going the way you wanted them to, 6) feeling that you couldn't do all the things you should, 7) being able to deal with everyday annoyances, 8) feeling that you were in control, 9) being angry with things that you had no influence over and 10) feeling that your problems were accumulating so much that you couldn't handle them. The test has a two-factor solution based on negative or positive formulations. Six of the 10 items are scored normally, i.e. are counted from 0 to 4 , while item \# 4, 5, 7, and 8 have reverse scoring, which means that $0=4,1=3$, and $2=2$. Counting item scores gives a total score. Maximum points are 40 and 0 is the minimum score possible. Results at approximately 13 are considered average [23]. Cut off for high stress scores is 20 points for normative populations, according to the literature [23].

\section{Stress sensitivity}

Stress sensitivity was measured using a 12-item questionnaire (see Appendix). Stress Sensitivity Inventory (SSI) [24], is a test of emotional (3 items), social (2 items), cognitive (3 items), physiological ( 2 items), and behavioral ( 2 items) aspects of stress sensitivity. Such factors are reported to be important parts in assessing one's ability to cope with stress [7] [11] [13] [15].

SSI reflects a person's assessment of their own sensitivity to stressful influences in which the items are answered with: $0=$ not at all; $1=$ very little; $2=\mathrm{a}$ 
little; 3 = some; $4=$ much. The points reflect how subjects experienced stressful periods Out of the 12 items, there is reverse scoring of item 5 , where $0=4,1=3$, $2=2$. Total scores were calculated. The range for SSI is from maximum 48 to minimum 0 . Results around 20 are considered the mean. High stress sensitivity scores start at 28 points according to summary reports about 6th-semester students from 2017-2019 [24].

\section{Signs of mental disorders}

Ss also filled out the Depression Anxiety Stress Scale (DASS-21) [16] [25] [26] [27] that consists of 21 items about three groups of mental disorders-depression, anxiety and chronic stress. DASS-21 has been used in many studies as an indication of the presence of signs of psychological disorders, but it should be cautioned that DASS-21 cannot be used as a psychiatric diagnostic tool. The 21 items measured 1) ability to "wind down", 2) amount of "mouth dryness", 3) ability to "feel anything positive at all ", 4) "difficulty in breathing", 5) "difficulty in to working up the initiative to do things", 6) "tendency to overreact", 7) "experienced trembling", 8) "using a lot of nervous energy", 9) "worry about panic and making a fool of myself", 10) "nothing to look forward to", 11) "becoming agitated", 12) "difficulty in relaxing", 13) feeling "downhearted and blue", 14) “tolerance", 15) "panic", 16) “enthusiasm", 17) “self-esteem", 18) “touchiness", 19) "heart rate", 20) "anxiety without reason", and 21) "meaningfulness of life". The questions were scored on an ordinal scale of 0 to 4 , where 0 was "never", 1 was "sometimes", 3 was "often" and 4 was "almost always". Total scores were first calculated with maximum is 63 minimum is 0 . According to the literature results of 9.4 are the mean and high DASS-21 total scores start at a cutoff of 20 points [26] [28].

Normative subscale scores for depression, anxiety and stress are presented below in Table 1. Ss scored subscale questions from 0 to 3 , where 0 was "does not apply to me", 1 was "to some degree", 2 was "significant degree", 3 was "very much; most often". Counting gives a total score. The maximum is 63 and the minimum is 0 . Results at 9.4 are the mean, while high DASS-21 total score cutoffs start at 20, according to literature [26] [28]. Also important are scores for subscales of Depression, Anxiety and Stress. Subscales are calculated on items 3, 5, 10, 13, 16, 17 and 21 for Depression, items 2, 4, 7, 9, 15, 19 and 20 for Anxiety and items 1, 6, 8, 11, 12, 14 and 18 for Chronic Stress. See Table 1 for normative scores.

Table 1. Normative scores for subscales of DASS-21 [29].

\begin{tabular}{cccc}
\hline & Depression & Anxiety & Stress \\
\hline Normal & $0-4$ & $0-3$ & $0-7$ \\
Mild & $5-6$ & $4-5$ & $8-9$ \\
Moderate & $7-10$ & $6-7$ & $10-12$ \\
Severe & $11-13$ & $8-9$ & $13-16$ \\
Extremely Severe & $14+$ & $10+$ & $17+$ \\
\hline
\end{tabular}




\subsection{Data Analysis and Statistical Methods}

Frequencies of PPS-10 scores in the two groups were first compared for any differences in distribution. Given similarities or differences in the distribution of group PPS-10 scores, the Stress Sensitivity Inventory was used as the main dependent variable and other factors from the other questions and scales represented the independent variables. Association analyses were conducted to attempt to explain variation by factors other than subject groupings. Thus, questions and scales were used to build explanatory models that could contribute to better understanding of the role of stress sensitivity among the whole sample and the two subsamples.

Reliability was assessed on scales and subscales using Cronbach's alpha. Validity was assessed using Spearman's rho correlations, response frequencies and chi-square tests.

Distribution and association analyses were accomplished using tables of percentage distributions including mean and standard deviation distributions, Student's t-tests/ANOVA for independent samples, Spearman's rho correlations, 2 $\times 2$ tables ( $\mathrm{Chi}^{2}$-test with continuity correction and odds ratios) and Nonlinear Logistic Regression with Hosmer-Lemeshow estimates of fit and Nagelkirke's $\mathrm{R}^{2}$ estimate of explained variance. All of the above were computed using statistical package SPSS 25 . Statistical significance was set at $\mathrm{P} \leq 0.05$. Dichotomous variable cutoffs were chosen on the basis of approximately one standard deviation over the mean score for each of the variables, unless otherwise described or rationalized above or in the Results.

\section{Results}

There was a significant difference in mean age as well as proportion of women to men between academic groups (Table 2). There was higher percentage of women among the dental students than the medical students. Dental students were significantly younger.

Dental students generally scored higher than medical students by means. This applies to both the DASS-21 total score, Cohen's PPS and SSI (Figure 1). Generally, women scored higher on mean scores for all tests (Figure 2).

Depression, Anxiety and Stress DASS-21 subscale scores among dental and medical students as illustrated in Figure 3, shows that dental students scored significantly higher than medical students on all three parameters based on ANOVA tests.

Table 2. Distribution of gender and mean age in academic groups.

\begin{tabular}{cccc}
\hline & WOMEN & MEN & MEAN AGE \\
\hline Dental students (DENT) & 43 & 6 & 22.9 \\
Medical students (MED) & 41 & 18 & 24.3 \\
Total & 84 & 24 & \\
\hline
\end{tabular}

$\mathrm{t}=$ DENT 100.3; MED 124.3; $\mathrm{P}<0.001$. 


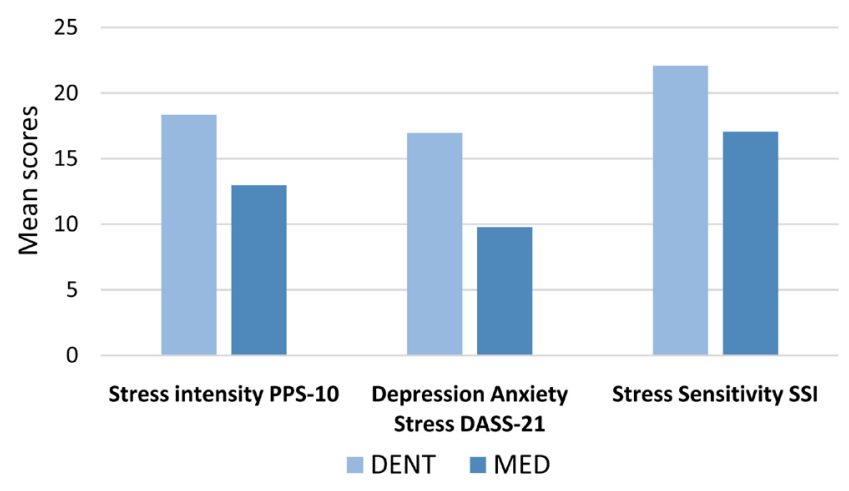

Figure 1. Descriptive statistics for PPS, DASS (total) for SSI dental and medical students.

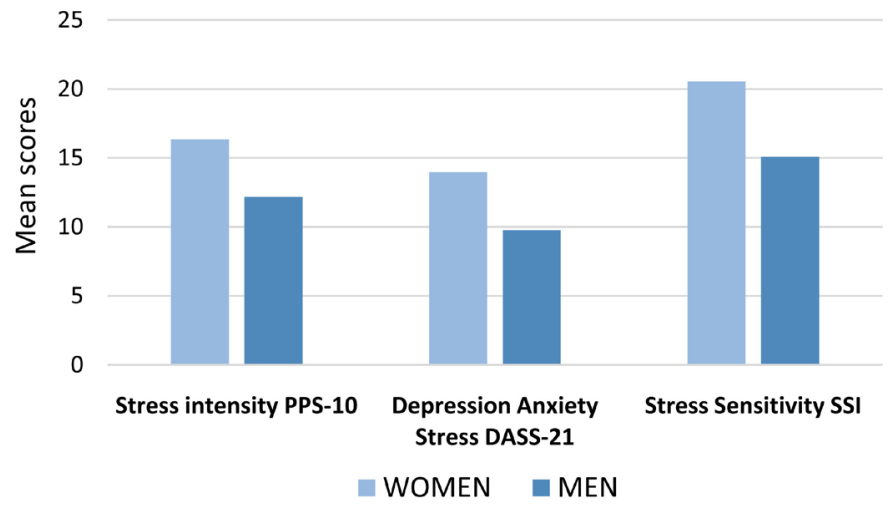

Figure 2. Mean scores $(\mathrm{N}=108)$ PPS, DASS (total) and SSI for men and women.

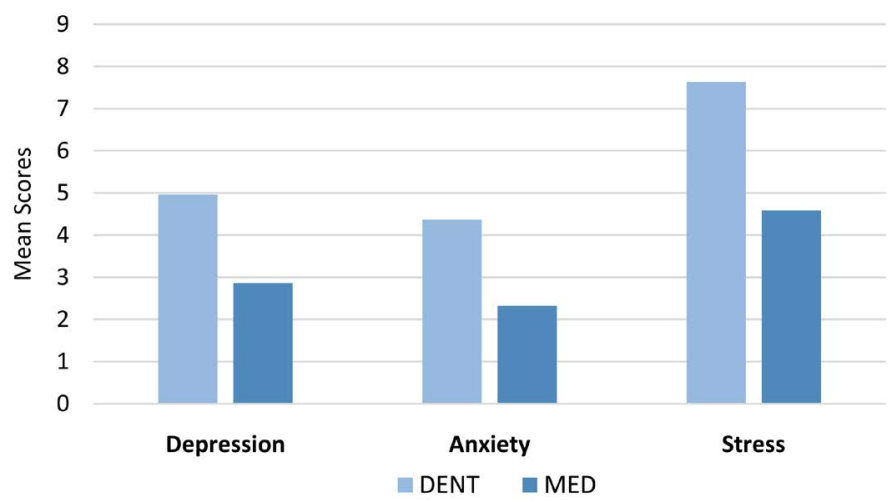

Figure 3. Mean scores for dental and medical students DASS-21 depression, anxiety and stress.

For both academic groups, there were significant and high correlations between stress intensity, stress sensitivity and signs of mental disorders as seen in Table 3 and Table 4. All psychometric tests were highly reliable according to Cronbach's alpha scores (Table 4).

\section{Discussion}

All subjects were recruited after about two months of clinical experience at the start of clinical teaching i.e. the transition from preclinical to clinical, in order to 
Table 3. Correlations between Cohens PPS, SSI og DASS total scores for DENT, MED and ALL.

\begin{tabular}{ccccc}
\hline & & PPS ${ }^{*}$ SSI & DASS ${ }^{*}$ SSI & PPS $^{*}$ DASS \\
\hline DENT $(\mathrm{n}=49)$ & Spearman's rho & 0.77 & 0.80 & 0.80 \\
& P-value & 0.00 & 0.00 & 0.00 \\
MED $(\mathrm{n}=59)$ & Spearman's rho & 0.58 & 0.53 & 0.60 \\
& P-value & 0.00 & 0.00 & 0.00 \\
ALL $(\mathrm{n}=108)$ & Spearman's rho & 0.75 & 0.74 & 0.78 \\
& P-value & 0.00 & 0.00 & 0.00 \\
\hline $\mathrm{F}=6.7, \mathrm{P}_{\text {depression }}=0.011, \mathrm{~F}=10.1, \mathrm{P}_{\text {anxiety }}=0.002, \mathrm{~F}=12.9, \mathrm{P}_{\text {stress }}=0.001$. &
\end{tabular}

Table 4. Correlations $(\mathrm{P}<0.001)$ for all test relationships, including DASS-21 subscale scores $(\mathrm{N}=108)$.

\begin{tabular}{ccccccc}
\hline & COHPPS & SSI & DASSTOT & DTOT & ATOT & STOT \\
\hline COHPPS & 1.000 & 0.75 & 0.78 & 0.66 & 0.68 & 0.73 \\
SSI & 0.75 & 10.00 & 0.73 & 0.57 & 0.71 & 0.68 \\
DASSTOT & 0.78 & 0.74 & 10.00 & 0.87 & 0.85 & 0.94 \\
DTOT & 0.66 & 0.57 & 0.87 & 1.00 & 0.55 & 0.73 \\
ATOT & 0.68 & 0.71 & 0.85 & 0.55 & 1.00 & 0.76 \\
STOT & 0.73 & 0.68 & 0.94 & 0.73 & 0.77 & 1.00 \\
\hline
\end{tabular}

Cronbach's $\alpha(\mathrm{N}=108)$ Cohens PPS = 0.91; SSI = 0.84; DASS total =0.93; Dep =0.89; Anx = 0.79; Stress = 0.88 .

capture stress phenomena at this critical period in professional development. Caution is required in generalizing from the results of the present study, since they were based on small sample sizes and convenience sampling from a university in Denmark. However, the findings are discussed below in relation to this context and according to similar or comparative findings in the literature on similar samples.

We expected the results to show that stress sensitivity and stress intensity levels of clinical dentistry and medicine students were high, and they were. According to the literature [23], to obtain a high stress score based on Cohen's PPS-10, required about 20 points, but 22 by our cutoff using one standard deviation. On average, 5th semester dental students scored mean 18.3 points which was closer to the cutoff than medical students with mean 13 points (see Figure 1). Given that 18.3 points was the mean, a large number of dental students scored over 22 points and thus perceived that they were highly stressed. Female dental students also appeared to be more stressed than male student counterparts, but the sample size for men was low, leading to the need for caution in interpreting these gender results. Generally, women scored higher, according to mean scores (Figure 2). These results on stress perceptions were also supported with similar findings on DASS-21 subscale scores for stress in Figure 3. 
We also expected to see signs of anxiety or depression among both dental and medical students and there were. The surveyed dental students scored a mean of 17 points on the DASS-21, while medical students scored 9.8 (Figure 1 and Figure 3). According to the literature [26] [28], a total score of 20 points on DASS-21 indicates meaningful signs of mental disorders. A large proportion of dental students scored more than 20 points, indicating meaningful signs of anxiety and depression.

These results showed, much as Schmitter et al. [18] and Murphy et al. [4], that dental students exhibit more negative stress experiences and signs of mental disorders as a result of negative stress than a similar sample of medical students. Results for current dental students were similar to DASS-21 results in a 2017 study by Basudan et al. [16] in Saudi Arabia, where the prevalence of depression, anxiety and stress among 277 dental students was high and the levels of these conditions were abnormal in more than half of the students.

The present study also investigated whether there were correlations between perceived stress intensity, stress sensitivity and signs of mental disorders among these new clinical students. As seen in Table 4, there were significant and good to high correlations between perceived stress intensity, stress sensitivity, and signs of mental disorders.

The results require some discussion on possible biases. As stated in the Introduction, studies have shown that stress among medical students falls off the further into their education they progress [4], whereas the stress level of dental students rises sharply at their third year, i.e. the first clinical year [4] [8]. This may have been an alternative explanation for our results, since third year dental students perceived higher levels of stress than did fourth year medical students. Also, looking at the composition of demographic variables by gender and age, there were significant differences between dental and medical students in this sample as described above (Table 2). Age and academic grouping in this sample could be seen as possible selection biases, since the clinical education starts a year later for medical students. However, the regression analysis confirmed that, in spite of psychometric test differences in bivariate analyses of stress and stress factors for gender and for dental and medical students, stress sensitivity was a potent common denominator for stress intensity perceptions and signs of mental disorders across age, gender and academic groups (Table 5). This was the main finding of the present study and indicated that stress sensitivity can be an intermediary variable affecting both perceived stress intensity and signs of mental disorders regardless of gender, age or academic group differences. Stress appraisal or stress sensitivity as an intermediary variable for stress perception and signs of mental disorders needs further research, also regarding pinpointing early need for counseling in order to prevent dysfunctional signs of stress during the clinical years.

Dissemination of these results are intended to increase awareness of educational faculties about the problem of negative stress experiences among dental or medical students and the need for stress management and prevention. High 
Table 5. Logistic regression analysis stress sensitivity vs. demographics and independent variables.

\begin{tabular}{|c|c|c|c|c|c|c|c|c|c|}
\hline & \multirow{2}{*}{ SSI $\geq 27$} & \multirow{2}{*}{ B } & \multirow{2}{*}{ Std. Error } & \multirow{2}{*}{ Wald } & \multirow{2}{*}{$\mathrm{df}$} & \multirow{2}{*}{ Sig. } & \multirow{2}{*}{$\operatorname{Exp}(B)$} & \multicolumn{2}{|c|}{$\begin{array}{l}\text { 95\% Confidence } \\
\text { Interval Exp (B) }\end{array}$} \\
\hline & & & & & & & & $\begin{array}{l}\text { Lower } \\
\text { Bound }\end{array}$ & $\begin{array}{l}\text { Upper } \\
\text { Bound }\end{array}$ \\
\hline \multirow{8}{*}{0} & Constant & -8.101 & 4.681 & 2.995 & 1 & 0.084 & & & \\
\hline & Gender & -1.734 & 1.236 & 1.970 & 1 & 0.160 & 0.176 & 0.016 & 1.989 \\
\hline & Age & 0.254 & 0.203 & 1.569 & 1 & 0.210 & 1.289 & 0.866 & 1.919 \\
\hline & MED or DENT & -0.787 & 0.761 & 1.071 & 1 & 0.301 & 0.455 & 0.102 & 2.021 \\
\hline & {$[\mathrm{COX} 22=0]$} & 2.072 & 0.686 & 9.119 & 1 & 0.003 & 7.938 & 2.069 & 30.453 \\
\hline & {$[\mathrm{COX} 22=1]$} & 0 & & & 0 & & & & \\
\hline & {$[\mathrm{DAX} 24=0]$} & 1.733 & 0.703 & 6.084 & 1 & 0.014 & 5.656 & 1.427 & 22.415 \\
\hline & {$[\mathrm{DAX} 24=1]$} & 0 & & & 0 & & & & \\
\hline
\end{tabular}

Goodness of Fit $\chi^{2}=23.1 ; \mathrm{df}=29, \mathrm{P}<0.001 ;$ Nagelkerke's $\mathrm{R}^{2}$ estimate of explained variance $=0.50$.

levels of stress may possibly lead to dental and medical students not getting the most out of their education [3] [4]. Stress can also have negative consequences in the form of depression and anxiety, which can have major personal consequences for the student e.g. in the form of extended study time, dysfunctional everyday life and lack of life energy. Negative stress can also lead to physical illness or emotional exhaustion and professional burnout [30]. It is even more problematic when it occurs early in the clinical education, since it can affect one's academic and clinical competencies as well as communication patterns and skills necessary for successful stress management as a practicing dentist [3] [4] [30] [31].

Increased faculty awareness may require both in-house psychological supports for individuals with high stress sensitivity and signs of depression or anxiety [32] as well as educational reforms. Clinical instructor training and calibration could be required, since inconsistent or harsh clinical instruction have often been named as external sources of stress load [7] [10]. Curriculum reform can also be necessary for better stress management in the pre-clinical to clinical transition. As an example, the Aarhus University Department of Dentistry initiated a mentor program in which students in their first two years of preclinical training are required to assist clinical dental students, in order to start adapting early on to the challenges of the clinical learning environment. This "Foal" program, as it is called, also has the added benefit of providing meaningfulness to younger students' pre-clinical education.

\section{Conclusion}

Dental and medical students in this sample often had high scores of stress perception intensity, stress sensitivity and symptoms of anxiety or depression. Results for the whole sample combined showed statistically significant moderate to 
high degrees of correlation between the three main measures in the study, stress intensity, stress sensitivity and signs of mental disorders. Stress Sensitivity Inventory appeared to be a reliable and excellent predictor of high perceived stress and signs of depression and anxiety that could be helpful to detect and prevent student psychosocial dysfunction in clinical learning environments. Further research about preconditions such as stress sensitivity is needed as a way to predict early on, which students might need counseling and extra support. Curriculum changes, which could affect prevention of stress overload, should also be considered in future research.

\section{Acknowledgements}

All authors had contributed substantially to data collection, analysis, and reporting of the work. The authors thank participants for taking time to participate in the study.

\section{Conflicts of Interest}

The authors confirm that this article content has no conflicts of interest.

\section{References}

[1] Elani, H.W., Allison, P.J., Kumar, R.A., Mancini, L., Lambrou, A. and Bedos, C. (2014) A Systematic Review of Stress in Dental Students. Journal of Dental Education, 78, 226-242.

[2] Alzahem, A.M., van der Molen, H.T., Alaujan, A.H., Schmidt, H.G. and Zamakhshary M.H. (2011) Stress amongst Dental Students: A Systematic Review. European Journal of Dental Education, 15, 8-18. https://doi.org/10.1111/j.1600-0579.2010.00640.x

[3] Alhajj, M.N., Khader, Y., Murad, A.H., Celebic, A., Halboub, E., Márquez, J.R., Macizo, C.C., Khan, S., Basnet, B.B., Makzoumé, J.E., de Sousa-Neto, M.D., Camargo, R., Prasad, D.A., Faheemuddin, M., Mir, S., Elkholy, S., Abdullah, A.G., Ibrahim, A.A., Al-Anesi, M.S. and Al-Basmi, A.A. (2018) Perceived Sources of Stress amongst Dental Students: A Multicountry Study. European Journal of Dental Education, 22, 258-271. https://doi.org/10.1111/eje.12350

[4] Murphy, R.J., Gray, S.A., Sterling, G., Reeves, K. and DuCette, J. (2009) A Comparative Study of Professional Student Stress. Journal of Dental Education, 73, 328-337.

[5] Haldorsen, H., Bak, N.H., Dissing, A. and Petersson, B. (2014) Stress and Symptoms of Depression among Medical Students at the University of Copenhagen. Scandinavian Journal of Public Health, 42, 89-95. https://doi.org/10.1177/1403494813503055

[6] Dyrbye, L.N., Thomas, M.R. and Shanafelt, T.D. (2006) Systematic Review of Depression, Anxiety, and Other Indicators of Psychological Distress among U.S. and Canadian Medical Students. Academic Medicine: Journal of the Association of American Medical Colleges, 81, 354-373. https://doi.org/10.1097/00001888-200604000-00009

[7] Moore, R. (2018) Psychosocial Student Functioning in Comprehensive Dental Clinic Education: A Qualitative Study. European Journal of Dental Education, 22, e479-e487. https://doi.org/10.1111/eje.12329

[8] Grandy, T.G., Westerman, G.H., Combs, C.E. and Turner, C.H. (1989) Perceptions 
of Stress among Third-Year Dental Students. Journal of Dental Education, 53, 718-721.

[9] Radcliffe, C. and Lester, H. (2003) Perceived Stress during Undergraduate Medical Training, a Qualitative Study. Medical Education, 37, 32-38. https://doi.org/10.1046/j.1365-2923.2003.01405.x

[10] Botelho, M., Gao, X. and Bhuyan, S.Y. (2018) An Analysis of Clinical Transition Stresses Experienced by Dental Students: A Qualitative Methods Approach. European Journal of Dental Education, 22, e564-e572. https://doi.org/10.1111/eje.12353

[11] Folkman, S., Lazarus, R.S., Dunkel, S., DeLongis, A. and Gruen, R.J. (1986) Dynamics of a Stressful Encounter: Cognitive Appraisal, Coping, and Encounter Outcomes. Journal of Personality and Social Psychology, 50, 992-1003. https://doi.org/10.1037/0022-3514.50.5.992

[12] Lazarus, R.S. and Folkman, S. (1984) Stress, Appraisal and Coping. Springer, New York.

[13] Crego, A., Carrillo-Diaz, M., Armfield, J.M. and Romero, M. (2016) Stress and Academic Performance in Dental Students: The Role of Coping Strategies and Examination-Related Self-Efficacy. Journal of Dental Education, 80, 165-172.

[14] Alzahem, A.M., Van der Molen, H.T., Alaujan, A.H. and De Boer, B.J. (2014) Stress Management in Dental Students: A Systematic Review. Advances in Medical Education and Practice, 5, 167-176. https://doi.org/10.2147/AMEP.S46211

[15] Lazarus, R.S. and Folkman, S. (1987) Transactional Theory and Research on Emotions and Coping. European Journal of Personality, 1, 141-169. https://doi.org/10.1002/per.2410010304

[16] Basudan, S., Binanzan, N. and Alhassan, A. (2017) Depression, Anxiety and Stress in Dental Students. International Journal of Medical Education, 8, 179-186. https://doi.org/10.5116/ijme.5910.b961

[17] Lloyd, C. and Musser, L.A. (1989) Psychiatric Symptoms in Dental Students. Journal of Nervous and Mental Disease, 177, 61-69. https://doi.org/10.1097/00005053-198902000-00001

[18] Schmitter, M., Liedl, M., Beck, J. and Rammelsberg, P. (2008) Chronic Stress in Medical and Dental Education. Medical Teacher, 30, 97-99. https://doi.org/10.1080/01421590701769571

[19] Bale, T.L. (2006) Stress Sensitivity and the Development of Affective Disorders. Hormones and Behavior, 50, 529-533. https://doi.org/10.1016/j.yhbeh.2006.06.033

[20] Hammen C. (2015) Stress Sensitivity in Psychopathology: Mechanisms and Consequences. Journal of Abnormal Psychology, 124, 152-154. https://doi.org/10.1037/abn0000040

[21] Hankin, B.L., Badanes, L.S., Smolen, A. and Young, J.F. (2015) Cortisol Reactivity to Stress among Youth: Stability over Time and Genetic Variants for Stress Sensitivity. Journal of Abnormal Psychology, 124, 54-67. https://doi.org/10.1037/abn0000030

[22] Harkness, K.L., Hayden, E.P. and Lopez-Duran, N.L. (2015) Stress Sensitivity and Stress Sensitization in Psychopathology: An Introduction to the Special Section. Journal of Abnormal Psychology, 124, 1-3. https://doi.org/10.1037/abn0000041

[23] Cohen, S. and Williamson, G. (1988) Perceived Stress in a Probability Sample of the United States. In: Oskamp, S. and Spacapan, S., Eds., The Social Psychology of Health, Sage, Newbury Park, 31-67.

[24] Moore, R. (2019) Stress Anxiety and Depression among First Year Danish Clinical Dental Students 2017-2019. Aarhus University, Aarhus, 1-18. 
[25] Antony, M., J. Bieling, P.J., Cox, B.W., Enns, M. and Swinson, R. (1998) Psychometric Properties of the 42-Item and 21-Item Versions of the Depression Anxiety Stress Scales in Clinical Groups and a Community Sample. Psychological Assessment, 10, 176-181. https://doi.org/10.1037/1040-3590.10.2.176

[26] Henry, J.R. and Crawford, J. (2005) The Short form of the Depression, Anxiety, Stress Scales (DASS-21): Construct Validity and Normative Data in a Large Non-Clinical Sample. British Journal of Clinical Psychology, 44, 227-239.

[27] Ng, F., Trauer, T., Dodd, S., Callaly, T., Campbell, S. and Berk, M. (2007) The Validity of the 21-Item Version of the Depression Anxiety Stress Scales as a Routine Clinical Outcome Measure. Acta Neuropsychiatrica, 19, 304-310. https://doi.org/10.1111/j.1601-5215.2007.00217.x

[28] Crawford, J., Cayley, C., Lovibond, P.F., Wilson, P.H. and Hartley, C. (2011) Percentile Norms and Accompanying Interval Estimates from an Australian General Adult Population Sample for Self-Report Mood Scales (BAI, BDI, CRSD, CES-D, DASS, DASS-21, STAI-X, STAI-Y, SRDS, and SRAS). Australian Psychologist, 46, 3-14. https://doi.org/10.1111/j.1742-9544.2010.00003.x

[29] Lovibond, S.H. and Lovibond, P.F. (1995) Manual for the Depression Anxiety Stress Scales. 2nd Edition, Psychology Foundation of Australia, Sydney.

[30] Moore, R. (2011) Occupational Stress among Dentists. In: Langan-Fox, J. and Cooper, C.L., Eds., Handbook of Stress in the Occupations, 1st Edition, Edward Elgar, Cheltenham, UK, 107-132.

[31] Serrano, C.M., Botelho, M.G., Wesselink, P.R. and Vervoorn, J.M. (2018) Challenges in the Transition to Clinical Training in Dentistry: An ADEE Special Interest Group Initial Report. European Journal of Dental Education, 22, e451-e457. https://doi.org/10.1111/eje.12324

[32] Adams, D.F. (2017) The Embedded Counseling Model: An Application to Dental Students. Journal of Dental Education, 81, 29-35. 


\section{Appendix}

\section{Stress Sensitivity Inventory}

Mark an $\mathrm{X}$ in a box beside each statement to indicate how you have experienced stressful periods.

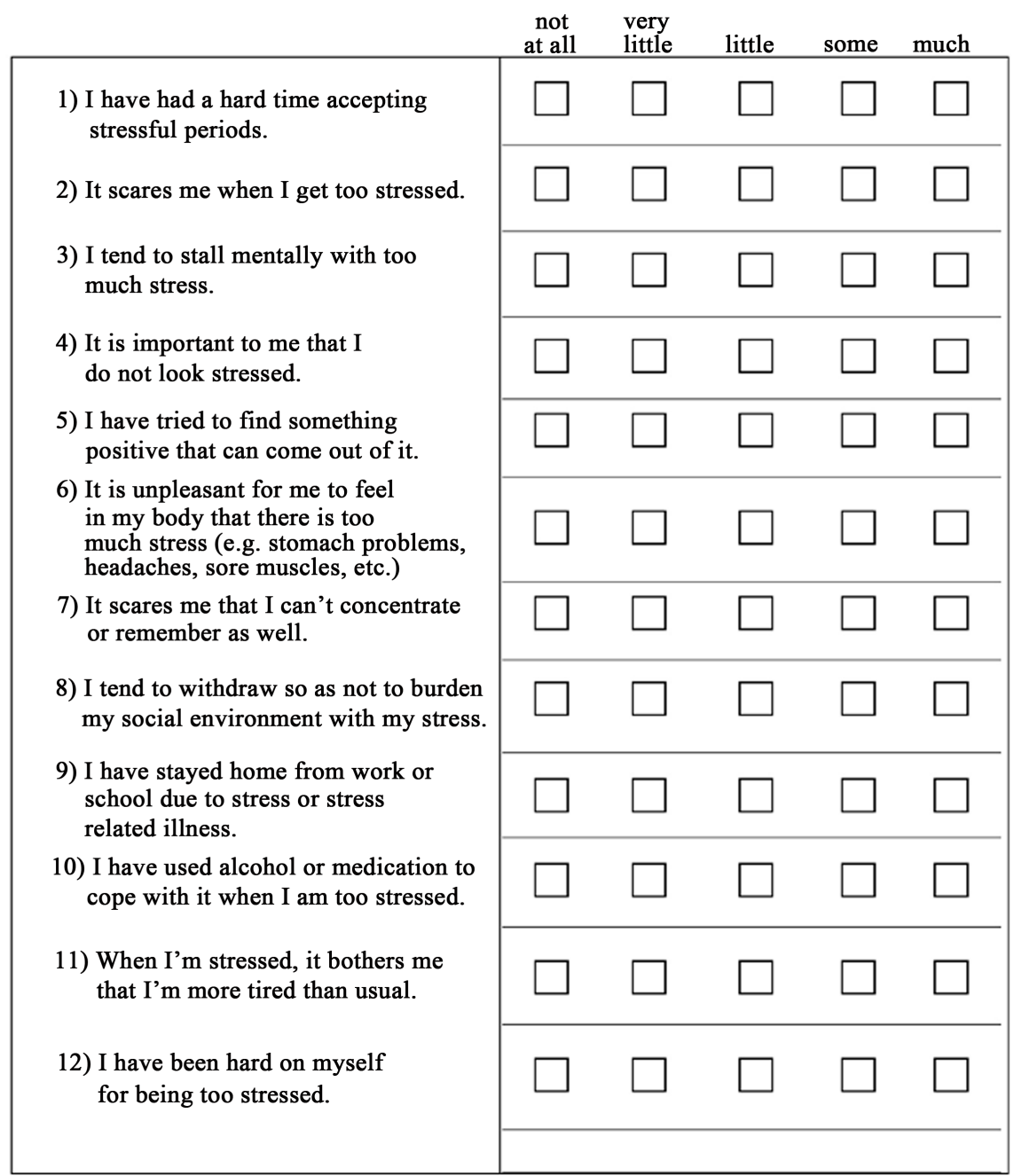

